\title{
Survivors of COVID-19 mostly recover from tubular proteinuria and acute kidney injury after hospital discharge
}

\author{
Antoine Bouquegneau ${ }^{1}$. Justine Huart ${ }^{1,2} \cdot$ Laurence Lutteri $^{3} \cdot$ Pauline Erpicum ${ }^{1,2}$. Stéphanie Grosch ${ }^{1}$. \\ Guillaume Résimont $^{1}$ - Patricia Wiesen ${ }^{4}$. Anne-Françoise Rousseau ${ }^{4}$. Christophe Bovy ${ }^{1,8}$. Jean-Marie Krzesinski ${ }^{1,2}$. \\ Marie Thys ${ }^{5}$. Bernard Lambermont ${ }^{4}$. Benoît Misset ${ }^{4} \cdot$ Hans Pottel $^{6} \cdot$ Gilles Darcis $^{7}$. Etienne Cavalier ${ }^{3}$. \\ François Jouret $^{1,2} \cdot$ Pierre Delanaye ${ }^{1,8}$
}

Received: 11 May 2021 / Accepted: 18 May 2021 / Published online: 5 June 2021

(C) Italian Society of Nephrology 2021

Keywords COVID-19 · Proteinuria · Acute kidney injury · Glomerular filtration rate

The coronavirus disease 2019 (COVID-19) is associated with acute kidney injury (AKI) [1]. Additionally, early observations in China showed a high prevalence of proteinuria and hematuria in patients infected by SARSCoV-2. These findings have since been confirmed in other countries. Proteinuria might result from a proximal tubular dysfunction. COVID-19-induced AKI and proteinuria have been associated with poor short-term outcomes in hospitalized patients [2, 3]. However, the middle- and long- term consequences of SARS-CoV-2 infection on kidney function

Antoine Bouquegneau and Justine Huart equally contributed as first authors.

Pierre Delanaye

pierre_delanaye@yahoo.fr

1 Service de Dialyse, Department

of Nephrology-Dialysis-Transplantation, CHU Sart Tilman, University of Liège (CHU ULiege), Liège, Belgium

2 Groupe Interdisciplinaire de Géno-Protéomique Appliquée, Cardiovascular Sciences, University of Liège, 4000 Liège, Belgium

3 Department of Clinical Chemistry, CHU Sart Tilman, University of Liège (CHU ULiege), Liège, Belgium

4 Department of Intensive Care, CHU Sart Tilman, University of Liège (CHU ULiege), Liège, Belgium

5 Department of Medico-Economic Information, CHU Sart Tilman, University of Liège (CHU ULiege), Liège, Belgium

6 Department of Public Health and Primary Care, KU Leuven Campus Kulak Kortrijk, Kortrijk, Belgium

7 Department of Infectious Diseases, CHU Sart Tilman, University of Liège (CHU ULiege), Liège, Belgium

8 Department of Nephrology-Dialysis-Apheresis, Hôpital Universitaire Carémeau, Nîmes, France remain unknown. In the present observational single-center study, we report the follow-up (F-U) of both proteinuria and estimated glomerular filtration rate (eGFR) in COVID-19 patients post hospital discharge [3].

All data were anonymized and the study had been approved by the Ethics Committee of ULiège Academic Hospital.

Patients older than 18 years of age admitted to Liège Academic Hospital between March 28th and April 30th, 2020 with PCR-confirmed COVID-19, for whom data concerning total proteinuria and/or urine $\alpha_{1}$-microglobulin were available were included in our study. A detailed description of the methodology has been previously published [3]. Briefly, serum creatinine and total proteinuria before COVID-19 were also collected when available. Total proteinuria (expressed in $\mathrm{mg} / \mathrm{g}$ of urine creatinine), urine $\alpha_{1}$ microglobulin and $\beta_{2}$-microglobulin were determined on a random spot. Proteinuria was staged according to the KDIGO (Kidney Disease Improving Global Outcomes). Urine $\alpha_{1}$-microglobulin was expressed in $\mathrm{mg} / \mathrm{g}$ of urine creatinine with a pathological threshold at $>15 \mathrm{mg} / \mathrm{g}$. Urine $\beta_{2}$-microglobulin was expressed in $\mathrm{mg} / \mathrm{L}$, with a pathological threshold at $>0.19 \mathrm{mg} / \mathrm{L}$. Hematuria was defined by the presence of more than 10 red blood cells per field. AKI during hospitalization (Hosp) was based on the KDIGO definition (after considering the serum level of creatinine at admission as the baseline value). Decreased kidney function was based on the CKD-Epidemiology equation (CKD-EPI) and using an age-calibrated definition. The same parameters were then followed after hospital discharge until August 28th, 2020 in the context of a global health follow-up of hospitalized COVID-19 patients established by the hospital. Data are expressed as median with quartiles. Comparison 
of independent and paired groups were performed using the Mann-Whitney U/Chi-square tests and Wilcoxon signed rank test/McNemar tests, respectively [3].

We included 153 hospitalized COVID-19 patients for whom urine data were available after a median period of 3 $(2 ; 5)$ days post admission (Hosp). Among the 153 patients, 30 patients died (mortality rate of $19.6 \%$ ). Of the 123 survivors, follow-up (F-U) urine analyses were available for 72 patients (58.5\%) (Flow chart in Supplementary Figure $\mathrm{S} 1)$. The median period between the day of hospital discharge and the last day of follow-up was $51(19 ; 93)$ days. The median age of our 72-patient cohort was 64 (58-75) years old, with a M/F gender ratio of $37 \%$ (Supplementary Table S1). Median proteinuria levels $(\mathrm{n}=72)$ at Hosp and F-U were $419(239 ; 748)$ and $79(47 ; 129) \mathrm{mg} / \mathrm{g}$, respectively $(\mathrm{p}<0.0001)$ (Table 1). During hospitalization, 15\% $(\mathrm{n}=11)$ had category 1 proteinuria, $43 \%(n=31)$ had category 2 and $42 \%(n=30)$ had category 3. At F-U, 83\% $(n=60)$ had category 1 proteinuria, $11 \%(\mathrm{n}=8)$ had category 2 and $6 \%$ $(n=4)$ had category 3 . Of important note, 2 of these latter 4 patients already had proteinuria prior to COVID-19, in the context of chronic uropathy $(\mathrm{n}=1)$, diabetic nephropathy $(\mathrm{n}=1)$, and one patient had a rheumatological disorder treated by cyclosporine and maintained by methotrexate. At Hosp and F-U, the median concentrations of urinary $\alpha_{1^{-}}$ microglobulin $(\mathrm{n}=66)$ were $50(25 ; 81)$ and $8(0 ; 19) \mathrm{mg} / \mathrm{g}$, respectively $(\mathrm{p}<0.0001)$. The $\alpha_{1}$-microglobulin concentration was higher than $15 \mathrm{mg} / \mathrm{g}$ in $88 \%$ and $29 \%$ of patients at Hosp and F-U, respectively (Table 1). At Hosp and F-U, the median concentrations of urinary $\beta_{2}$-microglobulin $(n=60)$ were $0.92(0.41 ; 4.52)$ and $0.00(0.00 ; 0.00) \mathrm{mg} / \mathrm{L}$, respectively $(\mathrm{p}<0.0001)$. Urine $\beta_{2}$-microglobulin was higher than $0.19 \mathrm{mg} / \mathrm{L}$ in $82 \%$ and $13 \%$ of patients at Hosp and F-U, respectively. Data on hematuria were available at F-U in 51 patients. At Hosp and F-U, 19\% and 12\% had hematuria, respectively (ns).

Hosp eGFR was lower than F-U eGFR: $81(62 ; 92)$ versus $87(66 ; 98) \mathrm{mL} / \mathrm{min} / 1.73 \mathrm{~m}^{2}(\mathrm{p}=0.0222)$. Still, decreased renal function was observed in 10/72 (14\%) patients at F-U compared to Hosp values. Among these 10 patients, 5 already presented with decreased renal function before COVID-19. In the remaining 5 patients with normal renal function before COVID-19, 4 developed category 3 AKI during hospitalization and 3 transiently required renal replacement therapy (RRT). Note that dialysis was withdrawn before hospital discharge in all 3 patients who required RRT during hospitalization.

Our F-U observations suggest that, although COVID-19 is associated with a high prevalence of tubular proteinuria and AKI, most patients $(\sim 80 \%)$ recover statu quo ante within $\sim$ a month post hospital discharge. Patients with persistent proteinuria at F-U already had previous clinical conditions favoring chronic proteinuria and/or suffered from the most severe AKI. The statistically significant, but probably not clinically relevant, difference between eGFR at Hosp and F-U remains in the range of normality. Patients with COVID-19 often presented with fever and gastrointestinal symptoms that may account for volume depletion and explain the slightly lower level of eGFR at Hosp compared to F-U. The main limitation of our study is the retrospective analysis of the data. Moreover, although we lack measurements regarding urine albumin (not reimbursed by the Belgian health system), protein immunofixation was available in more than $50 \%$ of patients at Hosp and F-U and clearly demonstrated a pattern of mixed proteinuria. Finally, the design of the current study did not allow us to formally distinguish acute tubular necrosis caused by septic conditions, potential toxicity of drugs or contrast agents during hospitalization or
Table 1 Renal parameters at the time of urine analysis during hospitalization and at follow-up

\begin{tabular}{|c|c|c|c|}
\hline & $\begin{array}{l}\text { Hospitalization } \\
\text { (Hosp) }\end{array}$ & $\begin{array}{l}\text { Follow-up } \\
(\mathrm{F}-\mathrm{U})\end{array}$ & $\begin{array}{l}\text { Wilcoxon signed } \\
\text { rank/McNemar } \\
\text { test }\end{array}$ \\
\hline $\begin{array}{l}\text { Creatinine }(\mathrm{mg} / \mathrm{dL})(\mathrm{n}=72) \\
\text { eGFR }\left(\mathrm{mL} / \mathrm{min} / 1.73 \mathrm{~m}^{2}\right)\end{array}$ & $\begin{array}{l}0.92(0.80 ; 1.09) \\
81(62 ; 92)\end{array}$ & $\begin{array}{l}0.87(0.76 ; 1.05) \\
87(66 ; 98)\end{array}$ & 0.04880 .0222 \\
\hline Decreased GFR (\%) (age adapted definition) & 20.8 & 14 & ns \\
\hline Decreased GFR (KDIGO) & 23 & 18 & ns \\
\hline Proteinuria $(\mathrm{mg} / \mathrm{g})(\mathrm{n}=72)$ & $419(239 ; 748)$ & $79(47 ; 129)$ & $<0.0001$ \\
\hline \multicolumn{4}{|l|}{ Proteinuria } \\
\hline Category $1(\%)$ & 15 & 83 & \\
\hline Category $2(\%)$ & 43 & 11 & \\
\hline Category $3(\%)$ & 42 & 6 & \\
\hline Urine $\alpha_{1}$-microglobulin $(\mathrm{mg} / \mathrm{g})(\mathrm{n}=66)$ & $50(25 ; 82)$ & $8(0 ; 19)$ & $<0.0001$ \\
\hline Urine $\alpha_{1}$-microglobulin $>15 \mathrm{mg} / \mathrm{g}(\%)$ & 88 & 29 & \\
\hline Urine $\beta_{2}$-microglobulin $(\mathrm{n}=60)(\mathrm{mg} / \mathrm{L})$ & $0.92(0.41 ; 4.52)$ & $0.00(0.00 ; 0.00)$ & $<0.0001$ \\
\hline Urine $\beta_{2}$-microglobulin $>0.19 \mathrm{mg} / \mathrm{L}(\%)$ & 82 & 13 & \\
\hline Hematuria $(>10$ per field $)(\%)(n=51)$ & 19 & 12 & ns \\
\hline
\end{tabular}


cytopathic lesions caused by SARS-CoV-2 itself, but the fact is that long-term consequences seem limited.

The present study confirms first reports suggesting that long-term renal sequelae of COVID-19 appear uncommon $[4,5]$. Similarly to other severe infectious diseases, a specific follow-up by nephrologists is recommended for survivors of COVID-19 who developed severe AKI and/or heavy proteinuria ( $\sim$ nephrotic range). These reassuring data need to be confirmed in larger cohorts.

Supplementary Information The online version contains supplementary material available at https://doi.org/10.1007/s40620-021-01075-1.

Acknowledgements We sincerely thank all physicians and nurses who take care of COVID-19 patients in the clinical wards and intensive care units.

Funding Grant Support: Fonds Léon Frédéricq. JH, PE and FJ are Fellows of the Fonds National de la Recherche Scientifique (FNRS), Belgium.

\section{Declarations}

Conflict of interest All the authors declare that they have no conflict of interest involving the work under consideration for publication.

Ethical approval All data were anonymized and the study had been approved by the Ethics Committee of ULiège Academic Hospital.
Informed consent For this study, consent is not required.

\section{References}

1. Hirsch JS, Ng JH, Ross DW et al (2020) Acute kidney injury in patients hospitalized with COVID-19. Kidney Int 98:209-218

2. Cheng Y, Luo R, Wang K et al (2020) Kidney disease is associated with in-hospital death of patients with COVID-19. Kidney Int 97:829-838

3. Huart J, Bouquegneau A, Lutteri L et al (2021) Proteinuria in COVID-19: prevalence, characterization and prognostic role. J Nephrol 34:355-364

4. Stockmann H, Hardenberg J, Aigner C et al (2021) High rates of long-term renal recovery in survivors of COVID-19-associated acute kidney injury requiring kidney replacement therapy. Kidney Int 99:1021-1022

5. Chan L, Chaudhary K, Saha A et al (2021) AKI in hospitalized patients with COVID-19. J Am Soc Nephrol 32:151-160

Publisher's Note Springer Nature remains neutral with regard to jurisdictional claims in published maps and institutional affiliations. 